\title{
Effect of Finishing Machine Parameters on Dimensional Stability of Single Lacoste Cotton Knitted Fabric
}

\author{
Md. Shaheen Iqbal, Md. Abdullah Al Mamun, Md. Abu Bakar Siddiquee, \\ A. K. M. Ayatullah Hosne Asif* \\ Department of Textile Engineering, Mawlana Bhashani Science and Technology University, Santosh, Tangail, Bangladesh
}

Email address:

asifte08@gmail.com (A. K. M. A. H. Asif), shaheeniqbal40@yahoo.com (Md. S. Iqbal)

${ }^{*}$ Corresponding author

\section{To cite this article:}

Md. Shaheen Iqbal, Md. Abdullah Al Mamun, Md. Abu Bakar Siddiquee, A. K. M. Ayatullah Hosne Asif. Effect of Finishing Machine Parameters on Dimensional Stability of Single Lacoste Cotton Knitted Fabric. Advances in Materials. Vol. 5, No. 5, 2016 , pp. 35-43. doi: 10.11648/j.am.20160505.12

Received: June 21, 2016; Accepted: September 1, 2016; Published: October 11, 2016

\begin{abstract}
The effect of finishing machine parameters on dimensional stability of single lacoste cotton knitted fabric was studied in this research. The dimensional properties of the single lacoste cotton knitted fabric such as shrinkage and spirality were investigated. All tests were carried out according to the ISO standards. In this research effect of dryer machine, stenter machine and compactor machine parameters on dimensional stability of single lacoste cotton knitted fabric were evaluated. The surface analysis of single lacoste cotton knitted fabrics were examined by scanning electron microscopy (SEM) on the samples of after drying, stentering and compacting respectively. The surface analysis of single lacoste cotton knitted fabric was also investigated by SEM on the softener treated and softener untreated samples after compacting process. From the result it was observed that fabrics show lowest shrinkage in both length and width wise and spirality for drying process than the stentering process. It was also observed that length wise and width wise shrinkage and spirality of the fabrics become gradually better by increasing the overfeed \% of both dryer and compactor machine. On the other hand length wise shrinkage of the fabrics become successively lower and width wise shrinkage of the fabrics become gradually higher by increasing the diameter of both dryer and compactor machine. But stretching of both dryer and compactor machine diameter has no significant influence on spirality. It was also noticed that width wise shrinkage of the fabric becomes gradually better and spirality becomes gradually higher by increasing the felt tension of the compactor machine.
\end{abstract}

Keywords: Single Lacoste Fabric, Scanning Electron Microscope, Shrinkage, Spirality

\section{Introduction}

Cotton knitted fabrics are quite popular in many sportswear, active wear and casual wear because of their excellent comfort and fit owing to their good air permeability and better stretch and recovery properties as compared to woven fabrics. The reasons behind the wider uses of knitted articles are excellent elasticity, light weight, low cost, smooth surface etc [1-2]. Manufacturing of knitted fabrics involves intermeshing of yarn loops where one loop is drawn through another loop to form a stitch [3].

The construction of a knitted fabric today is still frequently described in terms of courses and wales per unit length. Fabric shrinkage and spirality is the ultimate problem if the dimensional stability of the knitted fabric is not properly taken care. Spirality has an obvious influence on both the aesthetic and functional performance of knitted fabrics and the garments produced from them [4-5]. There are several factors which may be responsible for the instability of loop dimensions and consequently the poor dimensional stability of knitted fabric. This factors influencing the dimensional stability as well as the shrinkage and spirality of the knitted fabrics. Though the factors such as fiber characteristics, stitch length, machine gauge, yarn twist, knitting tension causes dimensional variations, the most prominent factor causing spirality in a single jersey fabric is the relaxation of torsional stresses in the yarn [6-8]. Spinning technology influences the degree of spirality in fabrics [9].

Reduction of dimensional stability of finished fabric is 
called shrinkage. It is important for the dyer and finisher to make an effort to remove as much shrinkage from the product as possible. Fabric shrinkage is a serious problem for knitwear, originating from dimensional changes in the fabric, particularly stitches [10]. During the knitting process, the yarn forming the fabric is constantly under stress. As a result, fabric on the machine is more distorted than the relaxed state. When the fabric is removed from the machine, it has time to relax and overcome these stresses which is easily recognizable by the changes in dimensions [11]. Shrinkage is a result of the combined effect of numerous factors such as relaxation, finishing, drying and effects of machinery. The effect of various fabric characteristics on the shrinkage behavior of weft knits is as important as that of the fiber characteristics [12-13]. Although almost all single-knit structures have a large tendency to shrink, but lacoste and pique fabric can shrink excessively, particularly in length direction, due to its comparatively open structure. Many techniques have been suggested to improve the dimensional stability of knitted cotton fabrics. Some studies suggest that shrinkage of cotton fabrics could be minimized by any treatment that prevents cotton fiber swelling on wetting [1415]. Knitted fabrics are prone to stretching and mechanical deformations. This is due to the fact that the yarns are put under a high stress factor whilst the fabric is being produced and finished [16]. The effect of yarn count and stitch length has great influence on shrinkage and spirality of single jersey cotton knitted fabric [17]. Use of different cross linking resins, such as DMDHEU has provided an acceptable solution to the poor dimensional stability problem [18]. However, application of such products may severely deteriorate the bursting strength of the treated fabric [19]. Tumble drying after washing may also be very efficient in controlling the dimensional stability of garments made from knits. But lower production of tumble driers and batch to batch quality variations limit their use for improving dimensional stability [20].

Knitting tensions along with other knitting parameters (such as tightness factor) and fabrics wet processing and finishing parameters also affect the dimensional stability of knits [21]. Mercerization is also one of the most important approaches for the improvement in dimensional stability of cotton knits [22]. Mechanical and chemical finishing procedures may reduce or increase the dimensional stability of the fabric. If relaxation dryers, compactors and/ or crosslinking agents are used, then the residual shrinkage after wet processing reduced [23]. Many researchers are engaged in research to investigate various effects on dimensional stability of cotton knitted fabric such as count, stitch length, knitting tensions and tightness factor, tumble drying etc. A little research has been found on effect of finishing machine parameters on dimensional stability of single lacoste cotton knitted fabric. That means finishing machine parameters having direct effect on dimensional stability of single lacoste cotton knitted fabrics. This research work will discuss about the effect of finishing machine parameters on dimensional stability of single lacoste cotton knitted fabric.
The aim of the present work will be on the: Study on the effect of drying and stentering process on dimensional stability of single lacoste cotton knitted fabric. Investigation on the effect of dryer machine parameters on dimensional stability of single lacoste cotton knitted fabric. Assessment of compactor machine parameters on dimensional stability of single lacoste cotton knitted fabric. Analysis of the surface of single lacoste cotton knitted fabrics after drying, stentering and compacting process by scanning electron microscopy (SEM). Investigation on the surface of softener treated and softener untreated samples of single lacoste cotton knitted fabric after compacting process by SEM.

\section{Materials and Methods}

\subsection{Materials}

\subsubsection{Cotton Yarn}

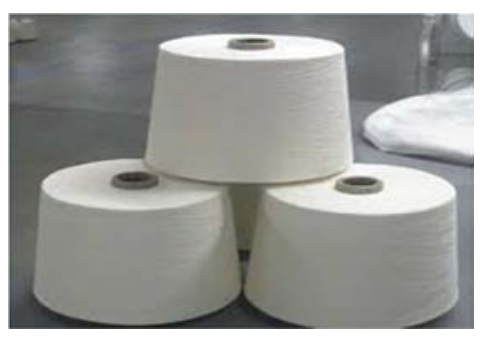

Fig. 1. Yarn cone.

Grey cotton yarn of $32^{\mathrm{s}} / 1$ (combed) was collected from the Apex spinning and knitting mills ltd. (Gazipur, Dhaka, Bangladesh) and used to manufacture single lacoste cotton knitted fabrics without any further treatment.

\subsubsection{Single Lacoste Cotton Knitted Fabric}

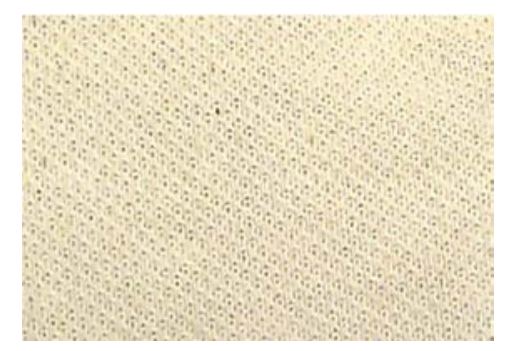

Fig. 2. Single lacoste cotton knitted fabric (grey).

Single lacoste cotton knitted fabrics were manufactured in Fukahama knitting machine by using $32 / 1$ combed yarn at stitch length $2.55 \mathrm{~mm}$. The GSM (gram per square meter) of the fabric at grey stage was found 180 and dyed with optical brightening agent in dilmenler dyeing machine.

\subsection{Chemicals}

(a) Softener: Matsoft NISB paste (non-ionic) was collected from Matex Bangladesh Ltd., Gazipur, Dhaka, Bangladesh.

(b) Detergents: ECE Phosphate and Sodium Perborate detergent were collected from ASM chemical supplier, Dhaka, Bangladesh. 


\subsection{Machineries Used in the Experiment}

\subsubsection{Tensionless Dryer Machine}

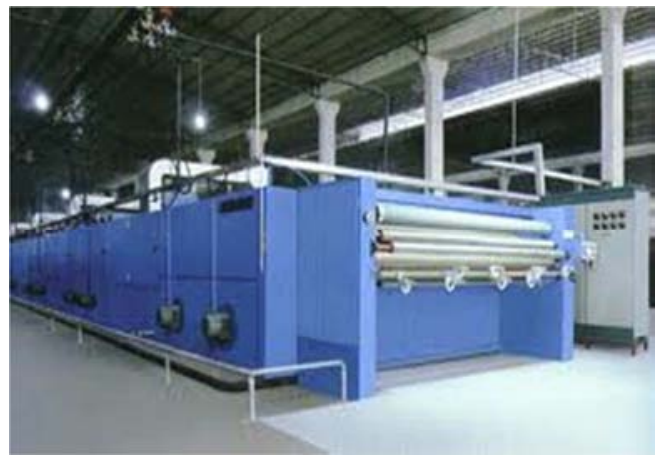

Fig. 3. Dryer machine.

In this research work, dryer machine was mainly used for controlling shrinkage and spirality of single lacoste cotton knitted fabrics.

\subsubsection{Stenter Machine}

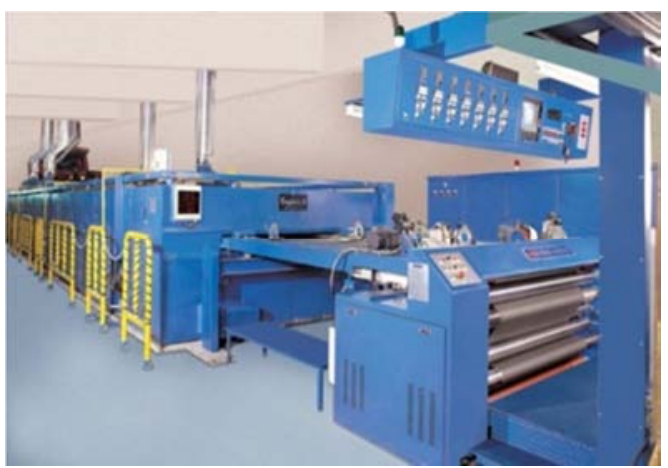

Fig. 4. Stenter machine

This machine was also used for drying and controlling dimensional stability of the fabrics in this research work.

\subsubsection{Compactor Machine}

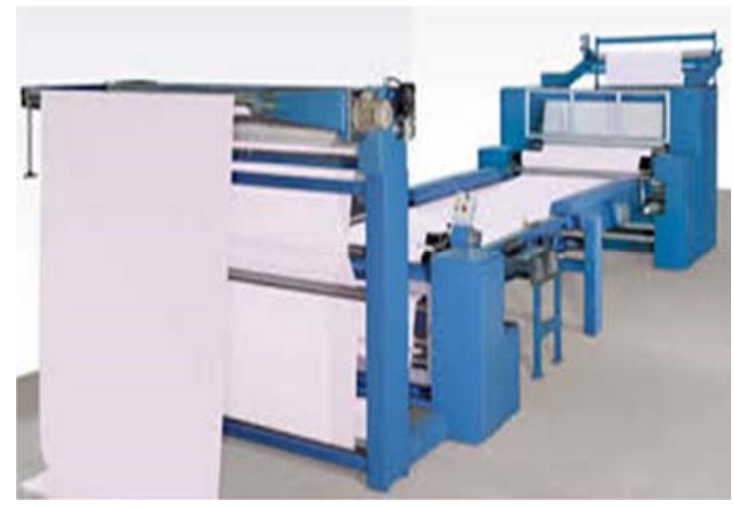

Fig. 5. Compactor machine.

In this research work compactor machine was mainly used for controlling shrinkage and spirality of single lacoste cotton knitted fabrics.

\subsubsection{SEM (Scanning Electron Microscope) Machine}

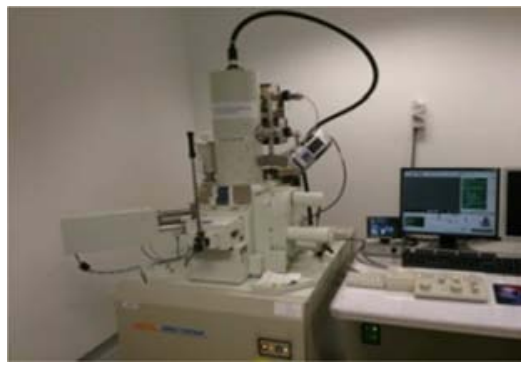

Fig. 6. Scanning electron microscope machine.

A scanning electron microscope (SEM) is a type of electron microscope that produces images of a sample by scanning it with a focused beam of electrons. In research work, five SEM images of the fabrics were taken by this machine.

\subsection{Methods}

\subsubsection{Methods of Dimensional Stability Testing}

The dimensional properties such as shrinkage and spirality of the single lacoste cotton knitted fabrics were evaluated according to BS EN ISO 6330:2001 method [24] and ISO 16322-3:2005 method [25] respectively and was carried out at physical testing laboratory of Apex holdings limited, Chandra, Gazipur, Bangladesh.

\subsubsection{Effect of Drying and Stentering Process on Dimensional Stability}

For measuring the dimensional stability of the single lacoste cotton knitted fabrics for drying and stentering process. At first five roll of fabrics were dried in LK \& LH stenter machine and another five roll of fabrics were dried in Asiasun tensionless dryer machine. Finally all fabrics were compacted in compactor machine. All parameters were kept constant for all fabrics in every machine. Then the shrinkage $\%$ of all fabrics were assessed to ISO 6330:2001 method and spirality\% of all fabrics were measured according to ISO 16322-3:2005 method.

\subsubsection{Effect of Dryer Machine Parameters on Dimensional Stability}

For assessing the dimensional stability of the single lacoste cotton knitted fabrics according to dryer machine parameters such as overfeed (\%) and stretching of diameter. For this research work at first five roll of single lacoste cotton knitted fabrics were dried in Asiasun tensionless dryer machine by increasing the overfeed $\%$ from (120-200) gradually where other parameter stretching of diameter was fixed. Then at second stage another five roll of fabrics were dried in dryer machine by stretching the diameter of the fabric from (1-5) inch gradually where overfeed $\% 200$ was fixed. After dryer operation shrinkage $\%$ of all fabrics were measured according to ISO 6330:2001 method and spirality\% of all fabrics were assessed according to ISO 16322-3:2005 method. 


\subsubsection{Effect of Compactor Machine Parameters on Dimensional Stability}

For evaluating the dimensional stability of the single lacoste cotton knitted fabrics for compactor machine parameters such as overfeed (\%), stretching of diameter and felt tension. For this research work at first five roll of fabrics were compacted in compactor machine by increasing the overfeed $\%$ from (120-200) gradually where other parameters such as stretching of diameter and felt tension were fixed. Then at second stage other five roll of fabrics were compacted in compactor machine by stretching the diameter of the fabric from (1-5) inch gradually where other parameters like overfeed $200 \%$ and felt tension $0.2(\mathrm{~kg})$ were fixed. Then at third time another five roll of fabrics were compacted in compactor machine by changing the felt tension from (0.2-1) $\mathrm{kg}$ where other parameters like overfeed $200 \%$ and stretching of diameter $5 "$ were fixed. After every experiment, shrinkage $\%$ and spirality $\%$ of all fabrics were measured according to ISO standards.

\section{Results and Discussion}

\subsection{Effect of Drying and Stentering Process on Length Wise and Width Wise Shrinkage of Single Lacoste Cotton Knitted Fabric}

Fig. 7 shows that length wise and width wise shrinkage of all fabrics become better for drying process than stentering process. Because dryer machine has conveyor belt system and net vibrating system which helps to shrink the fabric at length wise and width wise direction easily. In dryer machine, there is also no pinning and clip system in the drying zone. This leads to dry the fabric at tensionless state. This is due to impart lower tension on the fabrics when were dried in dryer machine than the stenter machine. So length wise and width wise shrinkage of all fabrics are better for drying process than stentering process.

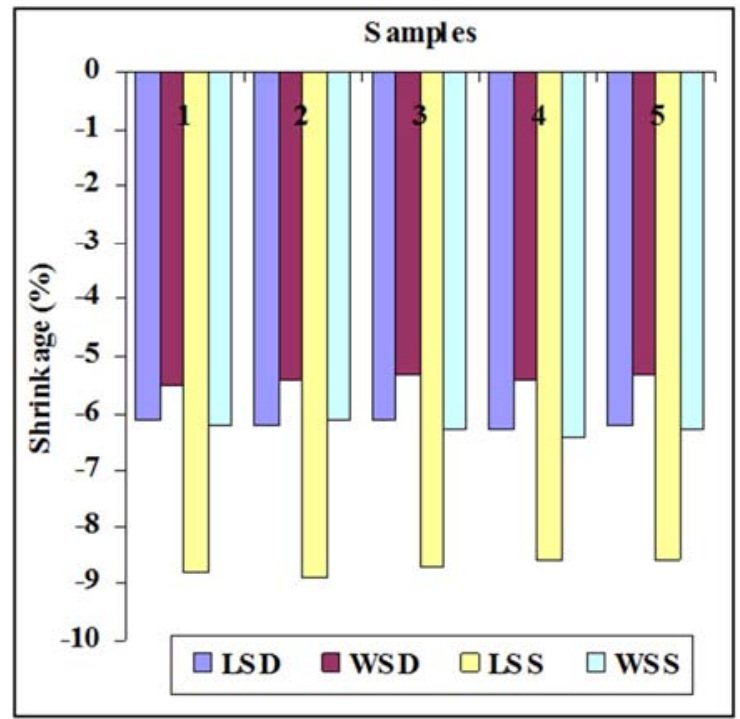

Fig. 7. Length wise and width wise shrinkage\% of single lacoste cotton knitted fabric for drying and stentering process.
Where, LSD and WSD mean length wise and width wise shrinkage for drying process respectively and LSS and WSS mean length wise and width wise shrinkage for stentering process respectively.

\subsection{Effect of Drying and Stentering Process on Spirality of Single Lacoste Cotton Knitted Fabric}

Fig. 8 signifies that the drying and stentering process have profound influence on spirality of single lacoste cotton knitted fabric. Fig. 8 shows that spirality of all fabrics are lower for drying process than stentering process. This is due to impart lower tension upon the fabrics in case of drying process than the stentering process. So spirality of all fabrics is lower for drying process than the stentering process.

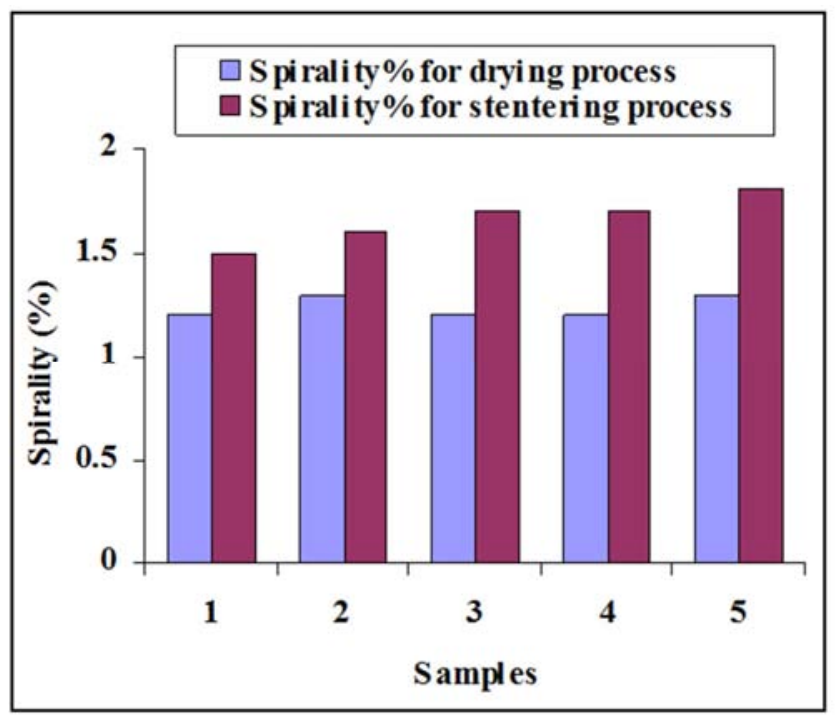

Fig. 8. Spirality of single lacoste cotton knitted fabric for drying and stentering process.

\subsection{Effect of Dryer Machine Parameters on Dimensional Stability of Single Lacoste Cotton Knitted Fabric}

Dimensional stability (shrinkage and spirality) of single lacoste cotton knitted fabric has been measured for overfeed $\%$ and stretching of diameter of dryer machine.

\subsubsection{Effect of Overfeed (\%) of Dryer Machine on Length Wise and Width Wise Shrinkage of Single Lacoste Cotton Knitted Fabric}

Fig. 9 indicates both length and width wise shrinkage become gradually better by increasing the overfeed $\%$ of dryer machine. This is due to get more relax or tensionless feeding of the fabric during drying operation. Higher the overfeed $\%$ means more feeding of fabric that leads to impart lower tension on the fabric during drying in both direction. So length wise and width wise shrinkage become gradually lower by increasing overfeed $\%$. 


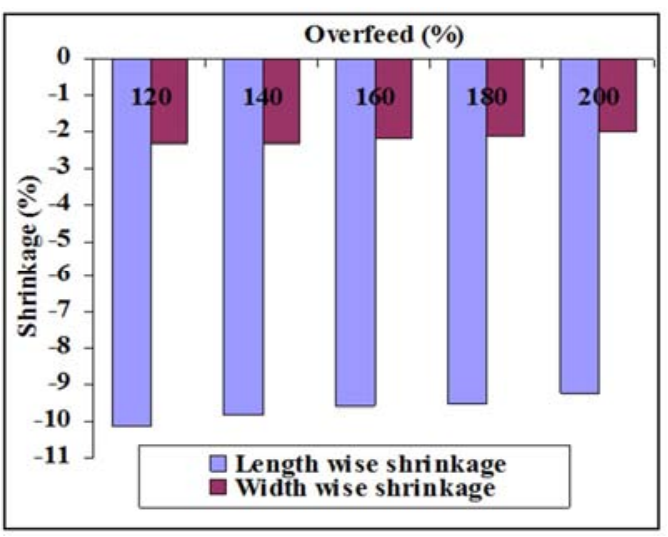

Fig. 9. Length wise and width wise shrinkage of single lacoste cotton knitted fabric for overfeed $\%$ of dryer machine.

\subsubsection{Effect of Overfeed (\%) of Dryer Machine on Spirality of Single Lacoste Cotton Knitted Fabric}

Fig. 10 points out that the overfeed $\%$ of dryer machine has very little effect on the spirality of the single lacoste cotton knitted fabric. Fig. 10 also shows that spirality becomes gradually lower by increasing the overfeed $\%$. This is due to achieve more relax or tensionless condition during drying process by increasing the overfeed $\%$ gradually.

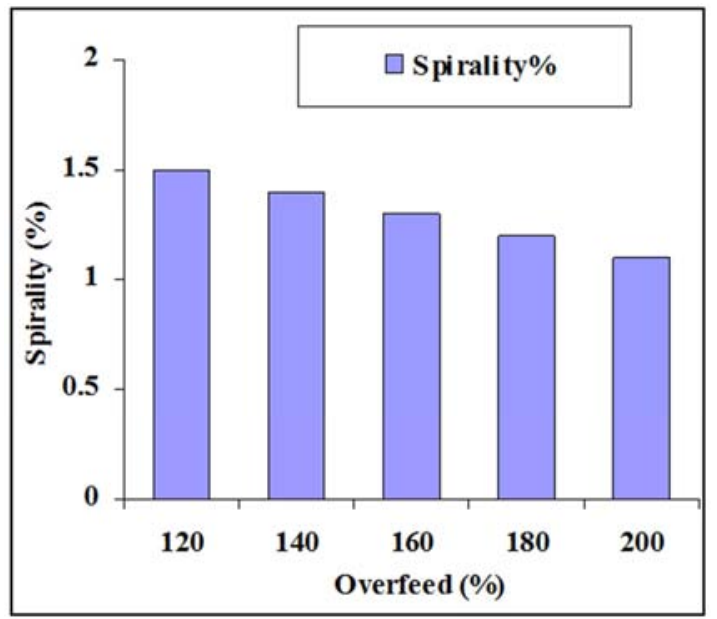

Fig. 10. Spirality of single lacoste cotton knitted fabric for overfeed $\%$ of dryer machine.

\subsubsection{Effect of Stretching of Diameter of Dryer Machine on Length Wise and Width Wise Shrinkage of Single Lacoste Cotton Knitted Fabric}

Fig. 11 designates that length wise shrinkage becomes gradually lower by increasing the diameter of dryer machine. This is due to get more shrinking of length wise direction of the fabric by increasing the diameter of the fabric. Because stretching of diameter of the fabric leads to achieve more shrinking in length wise direction of the fabric which leads to achieve more improvement of the length wise shrinkage gradually. On the other hand fig. 11 also indicates that the width wise shrinkage becomes gradually higher by increasing the diameter of dryer machine. This is due to impart more tension or stress on the width wise direction of the fabric.

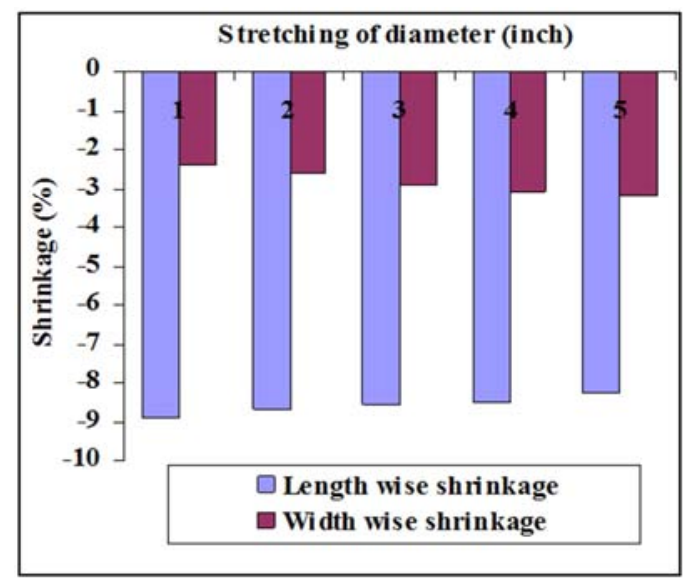

Fig. 11. Length wise and width wise shrinkage of single lacoste cotton knitted fabric for stretching of diameter of dryer machine.

\subsubsection{Effect of Stretching of Diameter of Dryer Machine on Spirality of Single Lacoste Cotton Knitted Fabric}

Fig. 12 points out that the stretching of diameter of dryer machine has no noticeable influence on spirality of single lacoste cotton knitted fabric.

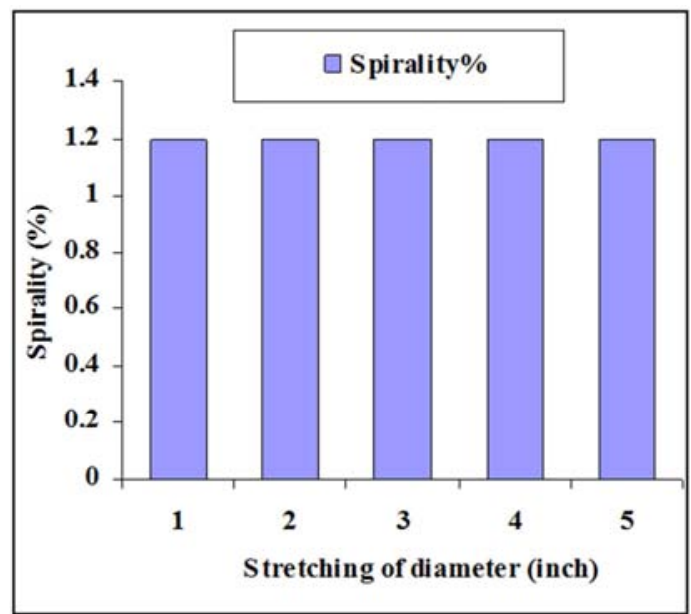

Fig. 12. Spirality of single lacoste cotton knitted fabric for stretching of diameter of dryer machine.

\subsection{Effect of Compactor Machine Parameters on Dimensional Stability of single Lacoste Cotton Knitted Fabric}

Dimensional stability (shrinkage and spirality) of single lacoste cotton knitted fabric has been measured for overfeed $\%$, stretching of diameter and felt tension of compactor machine.

\subsubsection{Effect of Overfeed (\%) of Compactor Machine on Length Wise and Width Wise Shrinkage of Single Lacoste Cotton Knitted Fabric}

Fig. 13 shows that both length wise and width wise shrinkage become gradually better by increasing the overfeed (\%) of the compactor machine. This is due to compaction; static friction is overcome by mechanical force. This is achieved by heated roll and felt of the compactors or 
compressive belt systems to force the length and width of the loop in a knit to become not only shorter, but also more round in configuration. This is due to get more relax or tensionless feeding of the fabric through the blanket or felt of the compactor. Higher the overfeed (\%) means more relax feeding of fabric through the felt where compaction of the fabric occurs. So length wise and width wise shrinkage of the fabric becomes gradually lower by increasing the overfeed (\%) of compactor machine.

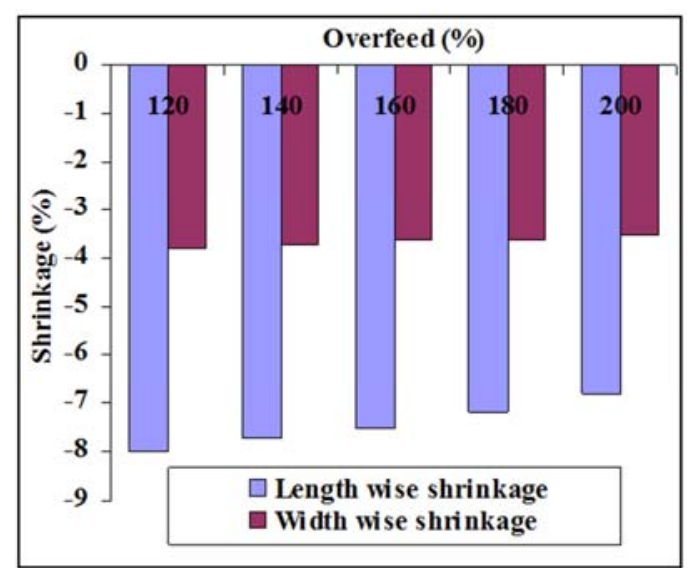

Fig. 13. Length wise and width wise shrinkage of single lacoste cotton knitted fabric for overfeed\% of compactor machine.

\subsubsection{Effect of Overfeed (\%) of Compactor Machine on Spirality of Single Lacoste Cotton Knitted Fabric}

Fig. 14 shows that spirality becomes gradually lower by increasing the overfeed $\%$. This is due to achieve more relax or tensionless condition during compacting process by increasing the overfeed $\%$ gradually.

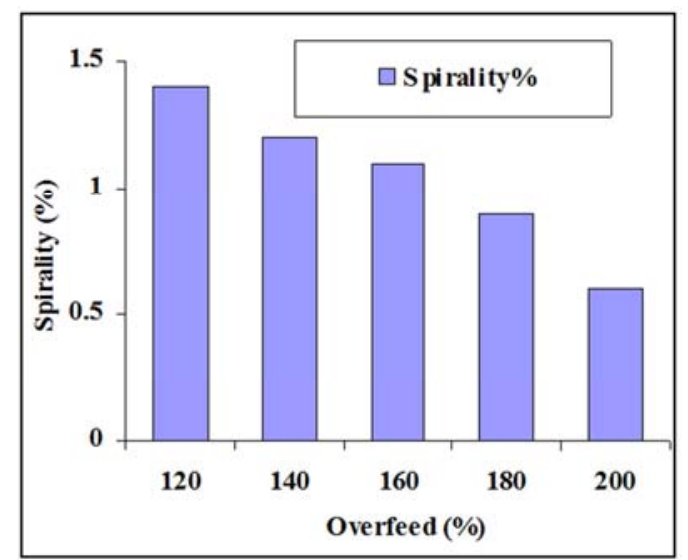

Fig. 14. Spirality of single lacoste cotton knitted fabric for overfeed\% of compactor machine.

\subsubsection{Effect of Stretching of Diameter of Compactor Machine on Length Wise and Width Wise Shrinkage of Single Lacoste Cotton Knitted Fabric}

Fig. 15 indicates that length wise shrinkage becomes gradually lower by increasing the diameter of compactor machine. This is due to get more shrinking of length wise direction of the fabric by increasing the diameter of the fabric. Because stretching of diameter of the fabric leads to achieve more shrinking in length wise direction of the fabric which leads to achieve more improvement of the length wise shrinkage gradually. On the other hand fig. 15 also indicates that the width wise shrinkage becomes gradually higher by increasing the diameter of compactor machine. This is due to impart more tension or stress on the width wise direction of the fabric which restricts the width wise direction of the fabric to get more compaction in compactor machine.

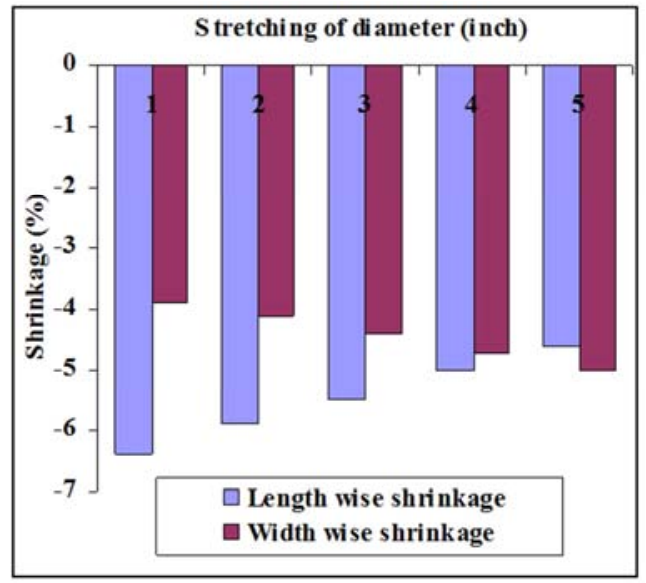

Fig. 15. Length wise and width wise shrinkage of single lacoste cotton knitted fabric for stretching of diameter of compactor machine.

\subsubsection{Effect of Stretching of Diameter of Compactor Machine on Spirality of Single Lacoste Cotton Knitted Fabric}

Fig. 16 represents that the stretching of diameter of compactor machine has no significant impact on spirality of single lacoste cotton knitted fabric. Spirality is same for all samples for stretching of diameter variations.

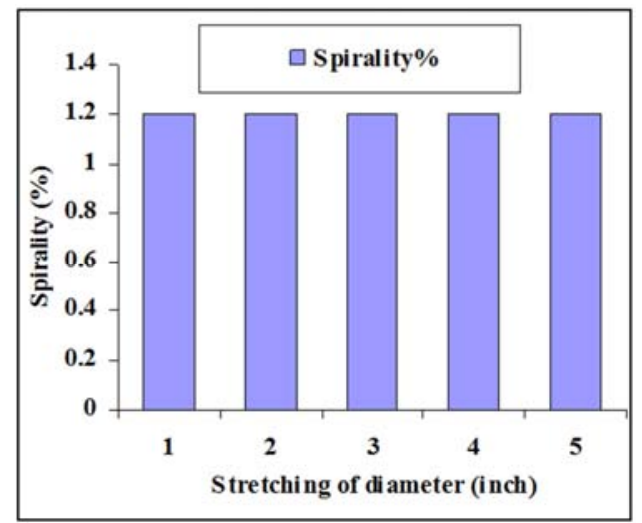

Fig. 16. Spirality of single lacoste cotton knitted fabric for stretching of diameter of compactor machine.

\subsubsection{Effect of Felt Tension of Compactor Machine on Length Wise and Width Wise Shrinkage of Single Lacoste Cotton Knitted Fabric}

Fig. 17 points out that length wise shrinkage becomes gradually higher by increasing the felt tension of compactor machine. This is due to impart more tension or stress on the length wise direction of the fabric which restricts the length 
wise direction of the fabric to get more compaction during compacting. On the other hand fig. 17 also shows that width wise shrinkage becomes gradually lower by increasing the felt tension. This is due to impart more tension or stress on the length wise direction of the fabric which leads to shrink the width wise direction loops of the fabric. Because in case of knitted fabric, when one direction of fabric stretches then other direction of fabric will be shrunk or loops of width wise direction will be shorten. So width wise direction loops of fabric easily get more compaction when passes through heated roller and felt or blanket of compactor machine. So width wise shrinkage of the fabric becomes gradually lower by increasing felt tension.

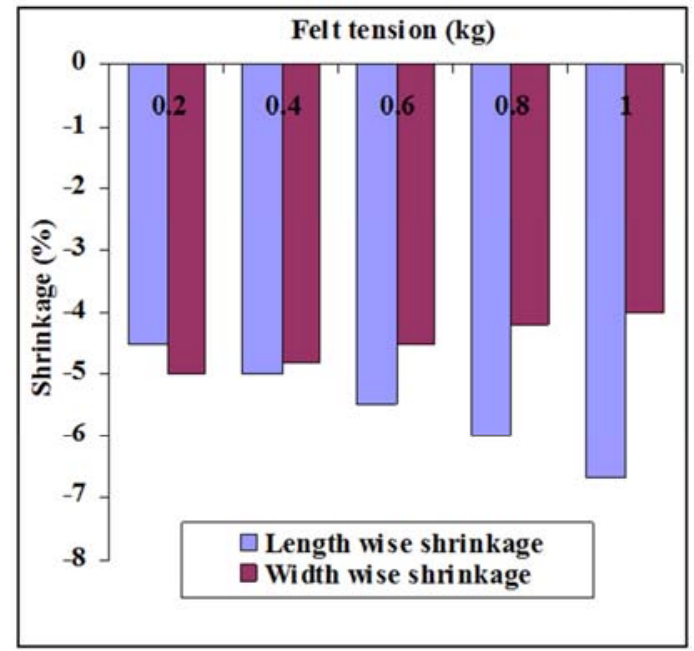

Fig. 17. Length wise and width wise shrinkage of single lacoste cotton knitted fabric for felt tension of compactor machine.

\subsubsection{Effect of Felt Tension of Compactor Machine on Spirality of Single Lacoste Cotton Knitted Fabric}

Fig. 18 designates that spirality becomes gradually higher by increasing the felt tension of compactor machine. This is due to impart more tension falls upon the fabric by increasing the felt tension gradually.

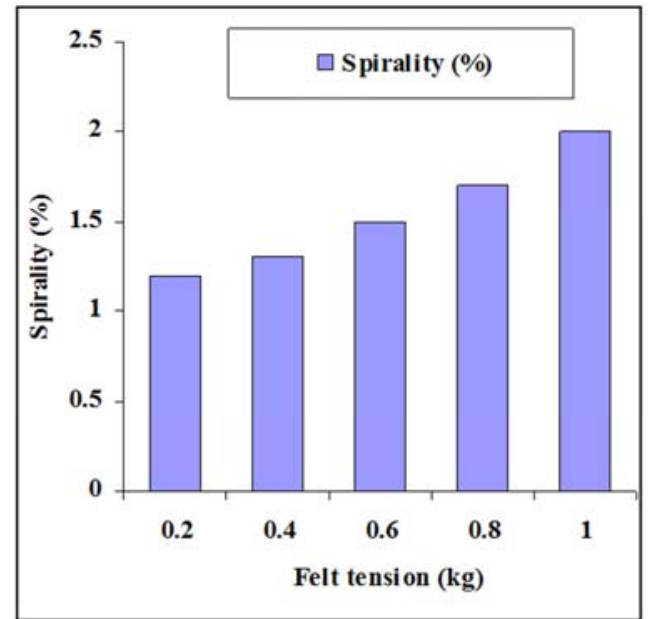

Fig. 18. Spirality of single lacoste cotton knitted fabric for felt tension of compactor machine.

\subsection{Analysis of Changes of the Fabric Surface Due to Drying, Stentering and Compacting Process on Single Lacoste Cotton Knitted Fabric by SEM}

The surface analysis of single lacoste cotton knitted fabrics were examined by scanning electron microscopy (SEM) on the samples of after (a) stentering, (b) drying and (c) compacting process respectively are presented below:
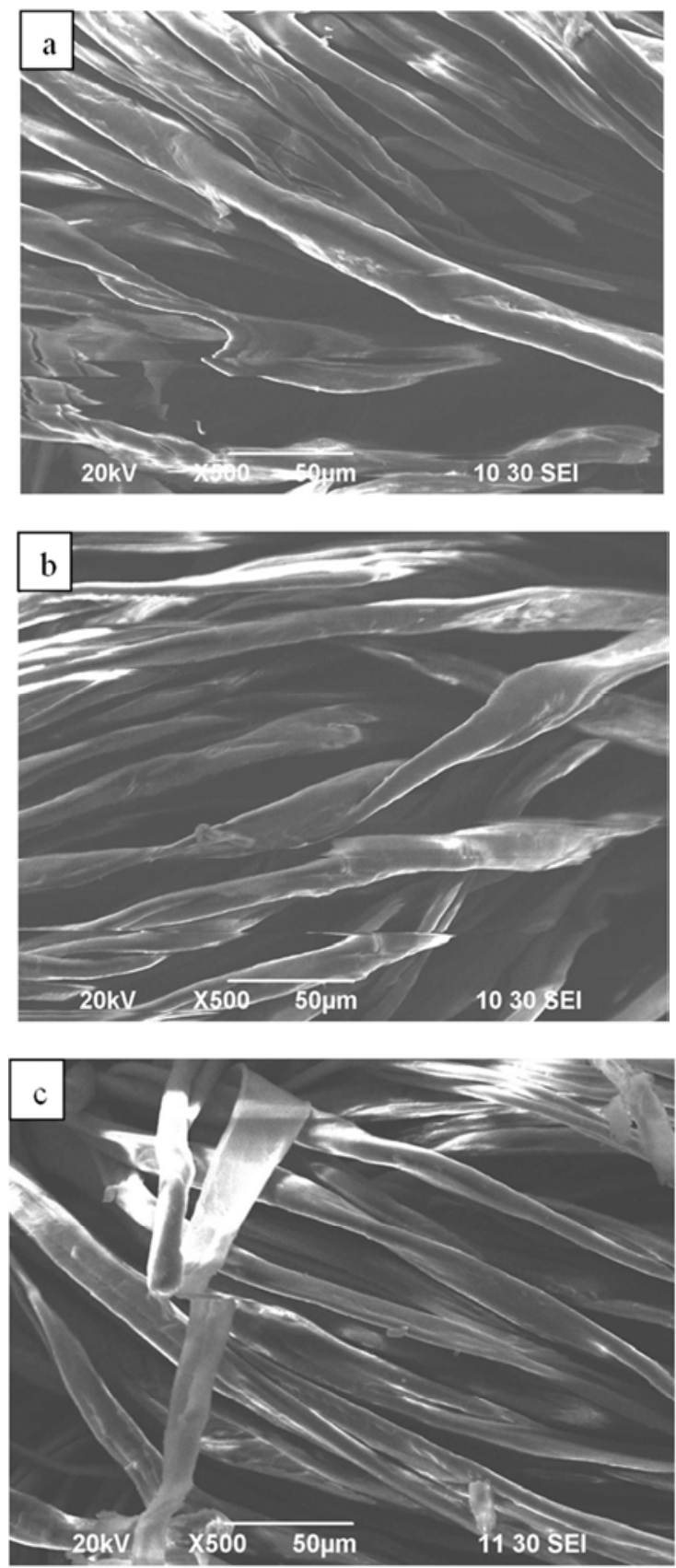

Fig. 19. SEM images (magnified) of the samples after (a) stentering, (b) drying and (c) compacting respectively

The figure 19 shows SEM images $(20.0 \mathrm{Kv} \times 500$, magnification 10000) of the samples after (a) stentering, (b) drying and (c) compacting respectively. The fig. 19(c) shows more parallel ridges of fiber and no fibrils (projecting fibers), ruptures and wrinkled surfaces. Fig. 19(c) also shows that 
compactness and finer cross-section of fibers on fabric surface that means the fabric achieved more stable dimension by mechanical compacting. On the other hand moderate parallel ridges of fiber and less fibrils (projecting fibers), moderate ruptures and wrinkled surfaces as shown in figure 19(b). It signifies the moderate compactness and crosssection of fibers on the fabric surface. But fig. 19(a) shows less parallel ridges, more fibrils (projecting fibers), more ruptures and wrinkled surfaces. It also signifies the looseness of fabric structure and coarser cross-section of fibers on fabric surface that means fabric is achieved less stable condition by stenter process than dryer or compactor process. So, dimensional stability becomes better for compactor sample than other dryer or stenter sample.

\subsection{Investigation on the Softener Treated and Softener Untreated Samples of Single Lacoste Cotton Knitted Fabric Surface After Compacting by SEM}

The surface analysis of single lacoste cotton knitted fabrics were examined by scanning electron microscopy (SEM) on the samples of (d) softener treated and (e) softener untreated after compacting respectively are presented below:
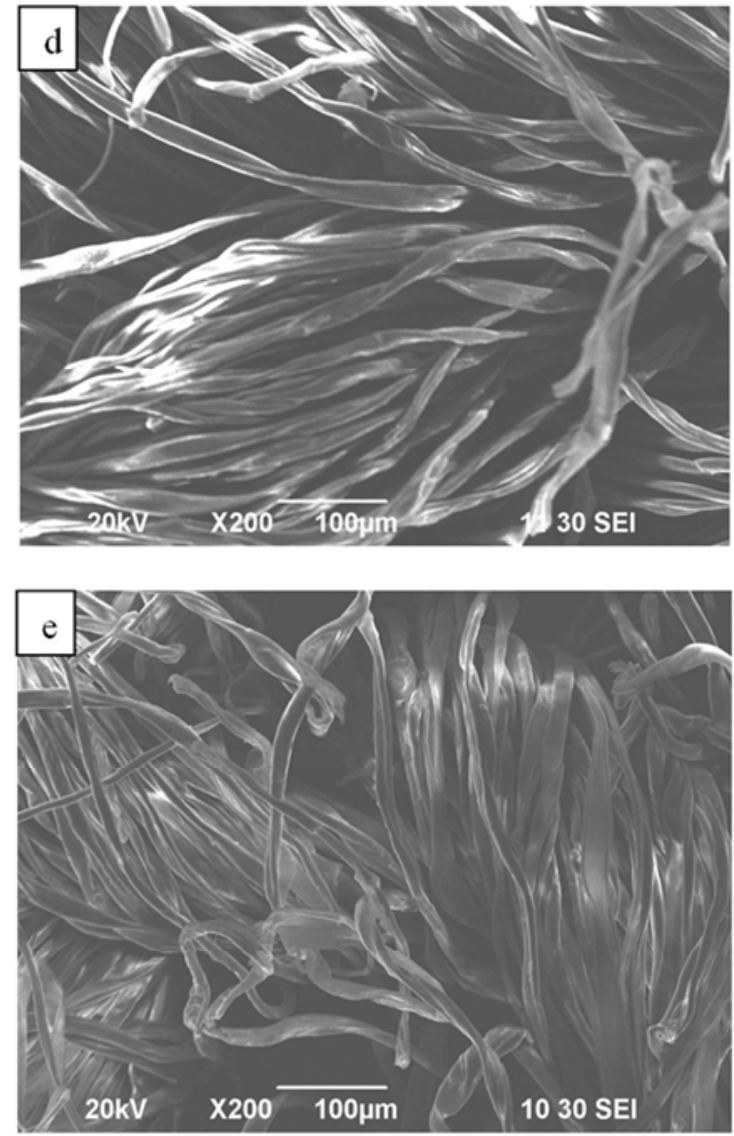

Fig. 20. SEM images (magnified) of the (d) softener treated and (e) softener untreated samples after (compacting) respectively

Fig. 20 shows SEM images $(20.0 \mathrm{Kv} \times 200$, magnification $4000)$ of the softener treated and untreated samples after compacting respectively. The fig. 20(d) shows more oriented fiber on the yarn surface. Fig. 20(d) also shows that less projecting fibers on the yarn surface than figure 20(e). This is due to softeners reduce the static friction, so that the yarn loops may be easily compacted. Softener also leads softer hand feeling of fabric. Better hand feeling of fabric leads to gain more compaction by compactor machine. So, fig. 20(e) shows more disoriented and projecting fibers on the yarn surface than figure 20 (d) due to not treated with softener.

\section{Conclusions}

- Fabrics showed lowest shrinkage in both length and width wise and spirality for drying process than the stentering process.

- It was observed that both length and width wise shrinkage and spirality becomes gradually lower with the increase of overfeed $\%$ of the dryer machine. On the other hand, it was also noticed that length wise shrinkage of the fabric becomes gradually lower and width wise shrinkage of the fabric becomes gradually higher by increasing the diameter of dryer machine. It was also observed that stretching of diameter of the dryer machine has no effect on spirality.

- It was noticed that dimensional properties (shrinkage and spirality) of the fabric becomes gradually lower with the increase of overfeed $\%$ of the compactor machine. On the other hand, it was also noticed that length wise shrinkage of the fabric becomes gradually lower and width wise shrinkage of the fabric becomes gradually higher by increasing the diameter of compactor machine. It was observed that stretching of diameter of the compactor machine has no significant effect on spirality. It was also observed that length wise shrinkage and spirality of the fabric becomes gradually higher with the increase of felt tension of the compactor machine. It was found that width wise shrinkage of the fabric becomes gradually lower by increasing the felt tension of the compactor machine.

- SEM images of compacted sample indicated that very little projecting fibre, more parallel ridges, no rapture and wrinkle surface that means the fabric achieved more stable dimension by mechanical compacting. On the other hand drying sample indicated that moderate parallel ridges of fiber and less fibrils (projecting fibers), moderate ruptures and wrinkled surface. It signifies that the moderate compactness and crosssection of fibers on the fabric surface. Finally stentering sample indicated that less parallel ridges, more fibrils (projecting fibers), more ruptures and wrinkled surfaces. It means that looseness of fabric structure and coarser cross-section of fibers on fabric surface.

- SEM image of softener treated sample (after compacting) indicated that more oriented and less projecting fibers on the yarn surface. On the other hand softener untreated sample (after compacting) also indicated that more disoriented and projecting fibers on the yarn surface due to not treated with softener. 


\section{References}

[1] N. Anbumani, Comparison of Woven and Knitted Fabrics; Knitting Fundamentals, Machines, Structures and Developments, $1^{\text {st }}$ Edition, New Age International: New Delhi, (2006) 4-5.

[2] Züleyha Değirmenci and Mehmet Topalbekiroğlu, Effects of weight, dyeing and the twist direction on the spirality of single jersey fabrics, Fibres and Textiles, 18 (2010) 81-85.

[3] Saufley Carl E, Continuous finishing of circular knit fabrics, Textile Chemist and Colorist, 24 (1992) 17-19.

[4] M. Abou-Ana, S. Youssef, C. Pastore and Y. Gowayed, Assessing structural changes in knits during processing, Textile Research Journal, 3 (2003) 535-540.

[5] Jiang Tao, R. C. Dhingra, C. K. Chan and M. S. Abbas, Effect of yarn and fabric construction on spirality of cotton single jersey fabrics, Textile Research Journal, 67 (1997) 57-68.

[6] W. Davis and C. H. Edwards, Spirality in knitted fabrics, Journal of Textile Institute, 25 (1934) 122-132.

[7] Haigh John, Loop distortion in plain knit fabrics, Wool Scientific Review, 64 (1987) 81-119.

[8] T.S. Nutting, Spirality in weft knitted fabrics, Hosiery Research Bulletin, 4 (1960) 18-31.

[9] M.D. De Araujo and G.W. Smith, The effect of yarn spinning technology on spirality, Textile Research Journal, 59 (1989) 350-356.

[10] Daiva MIKUČIONIENĖ and Ginta LAURECKIENÉ, The influence of drying conditions on dimensional stability of cotton weft knit fabric, Materials Science, 15 (2009) 64-65.

[11] Leticia Quaynor, Masaru Nakajima and Masaoki Takahashi, Dimensional changes in knitted silk and cotton fabrics with laundering, Textile Research Journal, 69 (1999) 285-291.

[12] Daiva Mikučionienè, The change of cotton plain knitted fabric shrinkage during its manufacture, Reports of International Conference Baltic Textile and Leather in Kaunas, (2003) 9597.

[13] Levent Onal and Cevza Candan, Contribution of fabric characteristics and laundering to shrinkage of weft knitted fabrics, Textile Research Journal, 73 (2003) 187-191.

[14] V.W. Tripp, A.T. Moore, I.V. de Gruy and M.L. Rollins, Location of areas of reaction in chemically treated cotton cellulose, Textile Research Journal, 30 (1960) 140-147.

[15] E. Franck and W. A. Reeves, Some effects of the nature of cross-links on the properties of cotton fabrics, Journal of the Textile Institute, 53 (1962) 22-36.

[16] S. C. Anand, K. S. M. Brown, L. G. Higgins, D. A. Holmes, M. E. Hall and D. Conrad, Effect of laundering on the dimensional stability and distortion of knitted fabrics, AUTEX Research Journal, 2 (2002) 85-100.

[17] Md. Abdul Hannan, Md. Mazedul Islam, S. M. Fijul Kabir, Abdullahil Kafi and Shamsuzzaman Sheikh, Effect of yarn count and stitch length on shrinkage, gsm and spirality of single jersey cotton knit fabric, European Scientific Journal, 10 (2014) 189-199.

[18] Wai Sze Lo, Tin Yee Lo and Ka Fai Choi, Effect of resin finish on dimensional properties of cotton knitted fabric, Journal of Textile Institute, 100 (2009) 530-538.

[19] Weilin $\mathrm{Xu}$ and $\mathrm{Yi} \mathrm{Li}$, Cotton fabric strength loss from treatment with poly carboxylic acids for durable press performance, Textile Research Journal, 70 (2000) 957-961.

[20] W. Fong and J.J. F. Knapton, The dimensional properties of knitted wool fabrics part iv: $1 \times 1$ rib and half-cardigan structures in machine-washing and tumble-drying, Textile Research Journal, 40 (1970) 1095-1106.

[21] S.A. Heap and J.C. Stevens, Influence of the spinner on the shrinkage of cotton circular knits, 23rd International Cotton Conference, Bremen, Germany, (1996).

[22] A.R. Moghassem and H.A. Tayebi, The effect of mercerization treatment on dimensional properties of cotton plain weft knitted fabric, World Applied Sciences Journal, 7 (2009) 1317-1323.

[23] Bobby W. Gordon Jr, D.L. Bailey, Brain W. Jones, Rob L. Stone and R.D. Noell, Shrinkage control of cotton knits by mechanical techniques, Textile Chemist and Colorist, 16 (1984) 25-27.

[24] ISO 6330:2001 Textiles - Domestic Washing and Drying Procedures for Textile Testing.

[25] ISO 16322-3:2005 Textiles - Determination of spirality after laundering - Part 3: Woven and Knitted garments. 